\title{
Macho versus Macho: um olhar antropológico sobre práticas homoeróticas entre homens em São Paulo*
}

\author{
Camilo Albuquerque de Braz***
}

\begin{abstract}
Resumo
Neste trabalho, minha proposta é tomar como foco de investigação práticas homoeróticas realizadas entre homens na cidade de São Paulo em espaços de sexo casual, grupal e/ou anônimo, envolvendo, em alguns casos, elementos fetichistas e/ou sadomasoquistas. Dados de campo preliminares, coletados sobretudo na Internet, permitem perceber a presença de discursos valorativos da masculinidade em parte destes contextos. A hipótese desta pesquisa é que tal valorização deve ser levada em conta no entendimento dos processos de materialização dos corpos e de construção da subjetividade entre esses homens.
\end{abstract}

Palavras-chave: Gênero, Sexualidade, Homoerotismo, Corporalidade, Subjetividade.

\footnotetext{
"Recebido para publicação em fevereiro de 2007, aceito em maio de 2007. Esse artigo é uma versão revisada e modificada do trabalho que apresentei no Seminário do Projeto Temático "Gênero e Corporalidades" (financiado pela Fapesp) do Núcleo de Estudos de Gênero - Pagu (Unicamp, agosto de 2006); no Simpósio Temático "Gênero, Corpo e Diversidade Sexual (Sexualidades), no VII Seminário Internacional Fazendo Gênero (Florianópolis, agosto de 2006); e no Grupo de Trabalho "Sexualidade, corpo e gênero", no $30^{\circ}$ Encontro Anual da ANPOCS (Caxambu, outubro de 2006). Trata-se do primeiro fruto de minha pesquisa de Doutorado, orientada pela Professora Dra. Maria Filomena Gregori, em curso na Área de Estudos de Gênero do Doutorado em Ciências Sociais da Unicamp. Agradeço às sugestões dos/as pesquisadores/as e de meus/minhas colegas do Pagu, além da leitura cuidadosa e do apoio imprescindível de minha orientadora.

** Doutorando em Ciências Sociais - área de gênero, Instituto de Filosofia e Ciências Humanas da Unicamp. camilo_braz@yahoo.com.br
} 
Macho versus Macho

Macho versus Macho:

an Anthropological Look at Homoerotic Practices Among Men

in São Paulo

\begin{abstract}
In this work, I intend to investigate homoerotic practices among men in São Paulo city in sites for casual, group or anonymous sex, involving sometimes fetishisms and/or sadomasochism. Preliminary field data, most of which collected in the Internet, shed light on the existence of discourses that grant great value to masculinity in some of these contexts. My hypothesis is that such valorization must be taken into account so as to fathom out the processes of body materialization and subjectivity construction in each of these men.
\end{abstract}

Key Words: Gender, Sexuality, Homoeroticism, Corporality, Subjectivity. 


\section{Contextualização de meus dilemas...}

Uma idéia exige uma lealdade que torna difícil qualquer astúcia. Ela mesma por vezes está errada, mas atrás dessa mentira reconheço ainda algo verdadeiro, que eu mesmo não consigo esconder (Maurice Blanchot, 2006).

No Brasil, a noção de "direitos sexuais" está sendo apropriada pelos movimentos homossexual e lésbico desde o início deste século, quando seus documentos e publicações a tomam como ponto de partida para enfrentar questões como as (hetero)sexualidades não-reprodutivas $e$ a invisibilidade das homossexualidades (Facchini, 2006). É possível até indicar que as práticas homoeróticas passam a ser reconhecidas e parcialmente desestigmatizadas. As recentes reivindicações de homossexuais à "família" e à legalização da "parceria civil" são exemplos de um processo que, para alguns/algumas, seria de "normalização" das (homo)sexualidades e vêm reacendendo o debate sobre os limites da sexualidade e o sentido da transgressão para o erotismo (Piscitelli et alii:Apresentação). Segundo Judith Butler (2003), o risco que se corre ao se pensar na legitimação das uniões homossexuais exclusivamente via Estado é o de vermos diversas práticas sexuais e relacionamentos, que ultrapassam a esfera da lei, tornarem-se ilegíveis ou insustentáveis, e novas hierarquias emergirem no discurso público. $\mathrm{O}$ interesse sobre as práticas aqui mencionadas reside em discutir e trazer elementos empíricos para a reflexão e os debates sócio-antropológicos sobre temas relacionados à sexualidade, às novas formas de erotismo e à sociabilidade nelas envolvidas e suas convenções. Acredito que esta pesquisa possa contribuir para suprir as lacunas derivadas da relativa escassez de estudos sobre prazer sexual, erotismo e desejo sexual, envolvendo formas diversas de expressão da sexualidade. ${ }^{1}$

1 Num panorama das pesquisas brasileiras em Ciências Sociais relativas a sexualidades e direitos sexuais no período de 1990 a 2002, publicado pelo Centro Latino-Americano em Sexualidade e Direitos Humanos (CLAM), aponta- 
Macho versus Macho

Vários dilemas me perseguem em minha pesquisa de doutorado. Uma das principais dificuldades que encontro atualmente é a tentativa de delimitação de meu objeto de estudo, ciente do risco da essencialização ao buscar nomeá-lo. Poderia chamá-lo de sexo "hardcore" entre homens, evocando a associação entre essas práticas e um certo conteúdo violento ou "duro". Poderia seguir as indicações de Gayle Rubin e chamá-lo de universo "gay leather" (Butler \& Rubin, 2003). Ou mesmo qualificá-lo como "sexo sujo" entre homens, inspirando-me em Mary Douglas (1976), para evocar seu possível caráter liminar, marginal, fronteiriço ou perigoso. Isso me autorizaria a pensar nas possíveis rearticulações das convenções de sexo, gênero, sexualidade e corporalidade neste universo - que é justamente o que busco entender. Não me sinto autorizado - $e$ talvez nunca venha a estar - a utilizar nenhuma dessas designações. Minha saída temporária e contingente para escapar a esse dilema é buscar classificações de maior neutralidade $e$ inclusão. Provisoriamente, posso afirmar que se trata de tomar como objeto uma parte do vasto universo dos homens que fazem sexo com homens na cidade de São Paulo. ${ }^{2}$ Especificamente, tenho em mente o sexo realizado em parte do mercado existente para essa finalidade (como cinemas pornôs, saunas, bares e clubes de sexo),

se uma ausência relativa de estudos sobre o erotismo, o prazer e o desejo sexual masculino e feminino, em comparação a um grande número de publicações em outras áreas, tais como sexualidade e juventude, sexualidades em tempos de AIDS ou prostituição, ver Citeli, 2005. Sobre a problemática dos direitos e políticas sexuais no Brasil, ver também Vianna \& Lacerda, 2004.

2 Sigo aqui as indicações de Júlio Simões em torno das controvérsias que envolvem as formas de categorização utilizadas para referir e classificar práticas erótico-sexuais entre pessoas do mesmo sexo. O uso da expressão "homens que fazem sexo com homens" seria, desse modo, uma tentativa de neutralizar a carga política e cultural de termos como "homossexual" ou "gay" (Simões, 2004). Apesar dessa designação, segundo o autor, não ser isenta de tais cargas e não resolver a questão da nominação dessas práticas, acredito que seu uso provisório possa ser justificado neste trabalho, uma vez que faço alusão a locais onde homens efetivamente, dentre outras coisas, fazem sexo entre si. 
envolvendo, em alguns casos, elementos "fetichistas" ou "sadomasoquistas $(\mathrm{s} / \mathrm{m})$ ". ${ }^{3}$ Tomo a liberdade de utilizar aqui tais expressões também de modo inclusivo, entendendo que a designação " $\mathrm{s} / \mathrm{m}$ " ou "fetiche" é contextualmente variada, e um de meus objetivos de pesquisa é entender como se configuram esses elementos da perspectiva dos sujeitos com os quais dialogo. O propósito analítico da escolha desses locais e práticas para a investigação constitui meu segundo dilema, que está relacionado com a possível rearticulação ou atualização das convenções de sexo, gênero, corporalidade e sexualidade por parte dos sujeitos nelas envolvidos, o que me leva a buscar inspiração na bibliografia que trata da chamada "estratificação sexual" nas sociedades contemporâneas. Um terceiro dilema é tentar delimitar um campo teórico no que diz respeito a gênero e sexualidade que me ajude a criar problematizações e problemas. Para isso, tenho buscado inspiração nas chamadas "teorias pós-estruturalistas" em gênero e sexualidade, que me levam a questionar os processos de produção das subjetividades e de materialização dos corpos nesses espaços, a partir de uma etnografia comparativa entre eles. Pensando na existência de uma matriz de inteligibilidade cultural hegemônica, que opera por meio da reiteração de normas que estabelecem a coerência dos corpos, talvez as práticas enfocadas neste estudo possam ser descritas como exemplos de descontinuidades, uma vez que rompem com a coerência estável entre sexo, gênero, desejo e com a materialidade corpórea. De certa forma, esses homens seriam "corpos abjetos" dentro de uma matriz heteronormativa (Butler, 2002). O abjeto designa, para Butler, aquelas "zonas invivíveis", "inabitáveis" da vida social,

que, sem dúvida, estão densamente povoadas pelos que gozam da hierarquia dos sujeitos, mas cuja condição de

\footnotetext{
$3 \mathrm{~S} / \mathrm{m}$ é uma abreviação para "sado-masoquismo". Esta sigla aparece em parte da bibliografia e designa jogos eróticos inspirados em fantasias de dominação e submissão (Ver Gregori, 2004; MacClintock, 1994 e 2003).
} 
Macho versus Macho

viver sob o signo do "invivível" é necessária para circunscrever a esfera dos sujeitos (Id. ib.:19-20).

A inteligibilidade não deve ser tomada como um campo fechado ou um sistema com fronteiras finitas, mas como um campo aberto. A prática humana seria constituída por atos repetidos que se instituem como normatividades hegemônicas ao encobrir seus efeitos. Sendo um campo em aberto, nas margens se encontram os "sujeitos" excluídos, que ajudam a entender a norma. ${ }^{4}$ Neste ponto, encontro outra justificativa analítica para a escolha de meu objeto de pesquisa. Pensar em abjeção em relação a uma matriz cultural hegemônica não significa, contudo, que não possamos pensar na criação de "matrizes alternativas" de inteligibilidade, nas quais a "coerência" seria dada por outros modos de arranjo entre categorias diversas. $\mathrm{O}$ fato de que os universos metropolitanos de pessoas que se relacionam afetivosexualmente com outras do mesmo "sexo" (sejam designados como "GLS", "GLBTTT" ou nenhum dos dois) criam em seu interior formas próprias de "inserção" e "abjeção" é algo que vem sendo apontado em estudos contemporâneos realizados em São Paulo. ${ }^{5}$ Meu olhar está voltado para as matrizes alternativas de inteligibilidade. Tomo como foco de investigação os múltiplos espaços voltados para o sexo entre homens em São Paulo para pensar na produção discursiva da subjetividade $e$ na materialização dos corpos dentro deles, levando em conta os diversos marcadores que operam e/ou são acionados nesses processos. Um quarto dilema diz respeito à preocupação éticoantropológica na realização da pesquisa de campo. Este ensaio é sobre esses dilemas. Não pretendo resolvê-los aqui e não sei se os

4 A autora se inspira aqui na leitura de Kristeva (1982) das idéias de Mary Douglas para a constituição da idéia de abjeção. Os corpos que "não são" tornam-se importantes para se entender as normas que constituem as subjetividades possíveis ou inteligíveis (os corpos que "são").

5 Ver, por exemplo, Simões, 2004; Simões \& França, 2005; Facchini, 2006. Vale salientar que os chamados queer studies tratam há tempos dessa questão. 
Camilo Albuquerque de Braz

resolverei algum dia. Minha tentativa é torná-los texto, sem que, com isso, percam a aura fantasmática que lhes faz interessante.

\section{Digressões etnográficas}

Muitos dos locais paulistanos voltados para o sexo entre homens contam com páginas na Internet, propiciando um rico material para um campo exploratório. Após minha ingênua $e$ fracassada tentativa de buscar pessoas dispostas a dialogar comigo em salas de bate-papo voltadas para o sexo, resolvi criar um perfil no Orkut ${ }^{6}$ explicando meus propósitos e pedindo voluntários, por meio de mensagens deixadas em comunidades relacionadas a este universo. Em pouco tempo, consegui uma lista de homens dispostos a conversar comigo via comunicador instantâneo (MSN). Alguns amigos e amigas também têm me ajudado a entrar em contato com os freqüentadores desses espaços, alguns deles bastante conhecidos neste universo, como proprietários de clubes $e$ organizadores de encontros sadomasoquistas e fetichistas. A entrada nessa rede tem me propiciado um ainda incipiente, mas promissor, trabalho de campo. ${ }^{7}$.

Analisando o "mercado gay" em algumas metrópoles dos Estados Unidos, Gayle Rubin (1993) fala do sucesso espetacular dos empresários gays na criação de uma economia homossexual diversificada. ${ }^{8}$ São Paulo é uma metrópole que conta, atualmente, com um expressivo e crescentemente segmentado mercado voltado para pessoas que se relacionam afetivo-sexualmente com outras do mesmo sexo (França, 2006). Dentro dele, há um vasto e diversificado mercado voltado para o sexo entre homens. Muitas boates e casas noturnas contam com um espaço específico para o sexo (os chamados dark-rooms). Há também muitas saunas

${ }^{6}$ Rede virtual para contatos eletrônicos que se transformou em "febre" no Brasil.

7 A pesquisa na internet vem sendo realizada desde o início de 2006. O trabalho de campo foi iniciado em outubro de 2006.

$8 \mathrm{Na}$ atualidade, assiste-se à segmentação desse mercado, ao incorporar novas preferências e demandas homoeróticas (Gregori, 2004). 
Macho versus Macho

voltadas para homens que fazem sexo com homens, bem como cruising-bars (que contam com cabines privativas, nas quais os freqüentadores podem realizar trocas erótico-sexuais), além dos grandes e antigos cinemas-pornôs do centro da cidade. Além disso, há espaços intitulados como "clubes de sexo" entre homens - alguns abertos ao público em geral. Em outros, para participar dos encontros, é preciso ser cadastrado. Esses clubes promovem festas e encontros "temáticos" diversificados.

Rubin realizou um estudo sobre a comunidade gay "leather" de São Francisco, nos EUA (Butler \& Rubin, 2003). Leather, para a antropóloga, é uma categoria mais ampla que inclui homens gays que praticam o sadomasoquismo, fazem a penetração anal com o punho, são fetichistas, másculos e preferem parceiros masculinos, sendo o couro (leather) um símbolo polivalente que teria sentidos diferentes para os vários indivíduos e grupos. Nessa comunidade, haveria uma articulação ou conexão entre preferências sexuais "não convencionais" e o masculino, o que não ocorreria entre heterossexuais ou lésbicas, onde esses elementos seriam arranjados de uma forma diferente. Seria, portanto, uma forma bastante peculiar $e$ interessante de combinar determinadas práticas sexuais com a rearticulação de convenções de sexo, sexualidade e gênero. ${ }^{9}$ Esses homens codificariam os sujeitos desejantes/desejados e os objetos desejantes/desejados como masculinos. Nesse sistema, um homem pode ser subjugado, reprimido, torturado $e$ penetrado $e$, ainda assim, manter a sua masculinidade, desejabilidade e subjetividade.

A pesquisa empreendida até aqui sugere que a valorização do "macho" como objeto de desejo permeia o universo de práticas homoeróticas em contextos bastante diversos. ${ }^{10}$ No

9 O desenvolvimento de tal comunidade seria parte de um longo processo histórico no qual a masculinidade teria sido reivindicada, afirmada $e$ reapropriada pelos homossexuais homens, nos EUA (Butler \& Rubin, 2003).

${ }^{10}$ Este é um exemplo dentre muitos outros: uma das comunidades do Orkut tem o sugestivo título de "Gay sim... bicha, NUNCA" e conta com quase 6,5 mil membros cadastrados. 
âmbito restrito da pesquisa não é diferente. Na maioria dos perfis cadastrados numa página de busca de parceiros para sexo e/ou relacionamento afetivo-sexual, os usuários buscam conhecer "caras machos", com postura "masculina", sem "trejeitos" ou "afetações". Apresentar-se como "discreto" ou "fora do meio" $e$ adquirir o status de "macho" parece ser uma maneira de se tornar mais valorizado sexualmente. Tanto aqueles que se identificam como "ativos" quanto os "passivos" buscam parceiros afetivosexuais "machos". Quase todos os usuários do site que buscam encontrar parceiros para sexo "grupal", no qual um homem deve ser penetrado por outros homens, frisam a exigência de que o "passivo" seja "macho".

Danilo mora em São Paulo, num bairro da Zona Sul, é branco, médico e tem 32 anos. Namora há dois anos um rapaz de 22 anos - em um "relacionamento aberto", que lhes permite ter experiências sexuais com outros homens. Danilo tem me acompanhado na pesquisa de campo e me ajudado a entrar em contato com os sujeitos desta pesquisa. Ele critica a postura do Clube X, localizado num bairro da Zona Sul, de limitar o acesso àqueles considerados "machos". No entanto, ao descrever os encontros sexuais dos quais participa (lá e em outros espaços variados), afirma que "o objeto de desejo é o macho". Mesmo aquele que é penetrado deve ser "macho", não "afeminado". "Foda entre machos" é a nomeação de Túlio para as práticas das quais participa - ele tem 23 anos, é pós-graduando numa universidade estadual, mora em Campinas - entre elas, orgias em clubes, saunas e encontros esporádicos com homens que conhece pela Internet. Para ir ao Clube X, Túlio precisou passar pelo cadastro e ser aceito como membro. Sempre que vai a esses espaços, Túlio é penetrado por muitos homens em uma mesma noite. Segundo ele, "precisa ser muito macho para agüentar passar por isso".

O Clube X é um espaço para sexo e orgias privado e seu site traz os roteiros das festas organizadas pelo grupo. Os participantes (ou pesquisadores...) devem, obrigatoriamente, concordar em não 
Macho versus Macho

vestir nenhuma peça de roupa lá dentro - "bottomless". Os temas das festas são variados, envolvendo uma série de "fetiches" homoeróticos. Na primeira vez em que estive lá, convidado pelo principal organizador dos encontros de "BDSM gay" e de "gays leathers" 11 da cidade, tratava-se de uma festa de "mascarados" (a única peça de roupa permitida eram máscaras fornecidas na entrada). Assim, há festas "estudantinas", para rapazes mais novos; "Boots", que evoca uniformes, especialmente militares; "Paizão", quando rapazes mais novos realizam trocas eróticas com homens mais velhos etc, além de festas sadomasoquistas, bem como um espaço especialmente criado para o exercício dessas práticas, dentro do clube (que conta com as chamadas slings, uma espécie de cadeira suspensa, feita de couro). Há uma série de itens que devem ser preenchidos para que um homem interessado possa ser membro dele: cadastrar-se (via site); ter uma aparência e uma atitude "masculina"; ter o peso proporcional à altura; ter entre 18 e 55 anos; ser "resolvido" e "open minded" - que, segundo alguns sujeitos de pesquisa, significaria não se restringir a fazer sexo com só um parceiro durante a festa, não fazer "carão", nem "bancar o difícil", estar, enfim, disposto mesmo a fazer sexo. Muito embora a consensualidade seja valorizada por meio da regra de que "não é não". ${ }^{12}$ Tenho me valido dessa regra para

\footnotetext{
${ }^{11}$ Os termos são dele.

${ }^{12} \mathrm{O}$ termo vem da sigla SSC - são, seguro e consensual ou consentido utilizada por adeptos/as como referência às práticas do BDSM. Segundo Zilli (2006), o B designa o Bondage (Imobilização), sendo o par B \& D para Bondage e Disciplina. O par D \& S para Dominação e Submissão, e o par S \& M para Sadismo e Masoquismo, ou Sadomasoquismo. O BDSM envolveria ainda práticas ligadas ao Fetichismo. É interessante tentar articular as informações em torno da "consensualidade" com as teorias a respeito do erotismo. A partir dos anos 50 do século passado, o tema passa a ganhar destaque na intelectualidade francesa, pela retomada dos escritos do Marquês de Sade e de Leopold von Sacher-Masoch (entre outros/as, Maurice Blanchot, Michel Leiris, Simone de Beauvoir, Roland Barthes, Gilles Deleuze, Georges Bataile). Comparando escritos dos dois autores, Deleuze (1983) discute a unidade entre sadismo e masoquismo, argumentando que a idéia de "sado-masoquismo" seja
} 
realizar a pesquisa. Embora os proprietários do clube, os organizadores das festas e alguns freqüentadores conheçam meus propósitos, a maioria das pessoas (que eu apenas observo) não. A consensualidade é, de certo modo, uma forma de manter minhas roupas figuradas num ambiente de nudez escancarada $e$ compulsória. Na página do Clube $\mathrm{X}$ na Internet, afirma-se que ele é voltado para "homens interessados em homens". Homens com "jeito de homem", com "voz de homem" e com "postura e vestimentas" masculinas. É esse discurso valorativo da "masculinidade", que poderia talvez ser chamado de "hipermasculinidade", o meu foco de interesse nesse trabalho.

\section{Digressões analíticas}

Existe uma vasta tradição de estudos sobre as homossexualidades no Brasil, que remonta à década de 1980 e tem a obra de Peter Fry (1982) como referência. A partir dessa matriz de pensamento, teríamos um sistema classificatório em que as práticas homoeróticas podem ser pensadas a partir de dois

analiticamente inconsistente sob vários aspectos. Para usar um jargão pósmoderno, eu diria que ela é discursivamente produzida no âmbito da medicina e da psicanálise. Essa é uma idéia especialmente interessante para quem toma o "s/m" contemporâneo como objeto de investigação. Analisando um sex-shop idealizado por lésbicas em São Francisco, Gregori (2004) chama a atenção para o processo de criação de um erotismo "politicamente correto", protagonizado por atores ligados à defesa das minorias sexuais nos EUA. Segundo a autora, estaria em curso um deslocamento do sentido de transgressão do erotismo para um significado cada vez mais associado ao cuidado saudável do corpo e para o fortalecimento do self. No que diz respeito às práticas $\mathrm{s} / \mathrm{m}$, a autora percebe uma espécie de neutralização ou domesticação dos traços e conteúdos violentos a elas associados. Nos sites dos clubes pesquisados até o momento são recorrentes as afirmações de que, para participar das festas, é preciso respeitar a regra de que "não é não". A idéia é que, dentro desses espaços, tudo é permitido, desde que seja consensual e praticado entre maiores de 18 anos. Para Deleuze, a noção de "contrato" e de "consentimento", tão cara à Masoch, está ausente em Sade. Isso leva à sugestão, a ser investigada, de que as práticas que reivindicam o rótulo de "s/m" atualmente sejam mais inteligíveis sob o que talvez possamos chamar de "registro do masoquismo". 
Macho versus Macho

modelos contrastantes. O primeiro, de modernidade e igualdade, remete a homens de camadas médias que se auto-identificam enquanto gays ou entendidos. $\mathrm{O}$ segundo, de tradição $e$ hierarquia, é composto por homens de camadas populares, cuja auto-identificação se daria (dentre outros fatores) a partir da posição assumida nas relações sexuais. Nesse modelo, as "bichas" seriam os passivos, considerados homossexuais, em oposição aos "bofes", que se valeriam de uma suposta ambi-sexualidade (Duarte, 2004). Esse modelo vem sendo problematizado por pesquisas recentes em São Paulo, que apontam para um processo de circulação dos ideais igualitários entre pessoas que se relacionam com pessoas do mesmo sexo de diferentes camadas sociais e colocam a necessidade de se repensar o entendimento da materialização dos corpos nesses contextos, levando em conta a intersecção entre diferentes categorias e marcadores (Facchini, 2006). Meu argumento é que as nuances relativas às convenções presentes no "sexo entre machos" podem ajudar nessa discussão.

A apropriação feita por Bataille (1987) dos escritos de Sade, perpassa boa parte da literatura sobre o erotismo. Inspirando-se em Sade, Bataille sugere que o erotismo deve ser pensado como transgressão às convenções morais. Gregori (2004) salienta que essa concepção é perpassada pelo posicionamento da relação masculino/feminino a partir de uma díade entre ativo e passivo, sendo ainda limitado o exame dos efeitos dessa tradição no que concerne à problemática de gênero. ${ }^{13} \mathrm{~A}$ questão que me coloco é se essa concepção do erótico via Bataille dá conta de explicar as práticas aqui referidas. Em Bataille, o gênero aparece fixo e cristalizado, ligado ao dimorfismo sexual e à associação entre sexo/gênero e posições sexuais. O corpo "violado", passivo, é "feminino", oposto ao masculino violador que o penetra. Vale salientar que essas idéias presentes em Bataille não aparecem no próprio Sade. ${ }^{14}$ Em termos "butlerianos", eu diria que

${ }^{13}$ Para uma análise da apropriação de Sade por Bataille, ver Gallop, 1981.

${ }^{14}$ A esse respeito, ver Carter, 1978. 
Bataille introduz o erotismo dentro da matriz heterossexual, impossibilitando que se pense o erótico fora da heteronormatividade. Pensar o aspecto erótico nas práticas aqui referidas requer desconstruir a própria idéia do que é erotismo. Um primeiro passo talvez seja levar a sério o que os sujeitos com quem tenho conversado dizem e dissociar a penetração do corpo de sua "feminização". Um segundo passo talvez seja pensar que quando esses homens se dizem "machos" não estão se opondo necessariamente à "feminilidade". A rejeição aqui é de quaisquer atributos - corporais, gestuais, comportamentais, relativos a sentimentos, sensações ou expectativas - que possam ser relacionados ao estereótipo do "afeminado". A valorização do "macho", os discursos que constituem o macho como objeto de desejo, não se opõem, nesse sistema, à feminilidade, mas à "bichisse".

Sem desconsiderar a importância da obra de Michel Foucault (1977) por retirar a possibilidade de naturalização $e$ mostrar a historicidade do dispositivo da sexualidade, é sabido que algumas/alguns teóricas/os feministas - incluindo Judith Butler (2003a) - o criticam por operar com certas categorias prédiscursivas, como os "corpos" e os "prazeres". ${ }^{15}$ Um dos desafios colocados para as atuais pesquisas, que tomam a materialização dos corpos e a produção das subjetividades como objeto de investigação, é pensar formas de articular (e não separar) não apenas gênero e sexualidade, mas uma série de outros marcadores de diferença na análise. Nesse sentido, tentei construir algumas reflexões sobre as teorias chamadas de pós-estruturalistas ou pós-modernas de gênero e sexualidade no pensamento social. Essas teorias apontam os limites da distinção entre sexo e gênero (inspirada no construcionismo social e na separação entre natureza e cultura) e ajudam a pensar na produção discursiva da corporalidade em contextos sociais diversos, levando em conta a

\footnotetext{
${ }^{15}$ A esse respeito, ver Piscitelli et alii, 2004:Apresentação.
} 
Macho versus Macho

operação de marcadores diferenciados que operam em sua materialização.

\subsection{Estratificação sexual}

A obra de Foucault é referencial para a chamada perspectiva "construcionista" de gênero e sexualidade, surgida nas ciências humanas na década de 1970, na medida em que ele retira qualquer possibilidade de naturalização do termo sexualidade. Foucault afirma que os desejos sexuais não são entidades biológicas pré-existentes, mas são constituídos no curso de práticas sociais específicas, determinadas historicamente. $\mathrm{O}$ autor ressalta os aspectos geradores da organização social do sexo e não os seus elementos repressivos, mostrando que há uma espécie de positividade nos dispositivos da sexualidade $e$ que novas modalidades estão sempre sendo produzidas (Foucault, 1977). A partir de sua obra surge a noção de um processo histórico de autonomização da sexualidade em relação a outros sistemas sociais como traço das modernas sociedades ocidentais. Essa alternativa "construtivista" permitiu quebrar visões essencialistas que buscavam entender as sexualidades em termos puramente biológicos.

Segundo Donna Haraway (2004:216), a "segunda onda" da política feminista em torno dos "determinismos biológicos" versus "construcionismo social" e das "bio-políticas das diferenças de sexo/gênero" "ocorrem no interior de campos discursivos préestruturados pelo paradigma de identidade de gênero, cristalizado nos anos 50 e 60". Para a autora, tal paradigma seria uma versão "funcionalista e essencializante" da idéia colocada por Simone de Beauvoir nos anos 40, de que não se nasce, mas torna-se "Mulher". Num contexto teórico e político em que se fazia necessária a quebra das visões biologizantes por parte do pensamento antropológico-feminista, surge a distinção entre sexo e gênero, tendo como base um trabalho de Gayle Rubin de 1975 (1986). A antropóloga norte-americana desenvolve a idéia do 
sistema de sexo/gênero ${ }^{16}$, mostrando, dentre outros fatores, como a relação entre reprodução e gênero perpassa certas teorias $e$ como ela se ancora num pressuposto que tende a aparecer de maneira mais velada: o pressuposto da naturalidade da heterossexualidade. Na leitura de Piscitelli (2003:213)

Em termos gerais, a organização social da atividade sexual humana estaria duplamente ancorada em algo que podemos considerar gênero $e$ na heterossexualidade compulsória.

A divisão sexual do trabalho ${ }^{17}$ e a construção psicológica do desejo (especialmente a formação edipiana) seriam os fundamentos de um sistema de produção de seres humanos que atribuiria aos homens direitos sobre as mulheres que elas próprias não teriam sobre si próprias. Segundo Henrietta Moore (1997), a distinção entre sexo biológico e gênero mostrou ser absolutamente crucial para o desenvolvimento da análise feminista nas ciências sociais dos anos 70 e 80 , porque possibilitou demonstrar que as relações entre mulheres e homens e os significados simbólicos associados às categorias "mulher" $e$ "homem" são socialmente construídos e não podem ser considerados naturais, fixos ou predeterminados.

\footnotetext{
${ }^{16} \mathrm{O}$ sistema sexo-gênero é o conceito elaborado pela autora e se refere a um conjunto de arranjos através do qual a "matéria- prima biológica" do sexo e da procriação humana é moldada pela intervenção humana e social e satisfeita de forma convencional. Tal sistema constituiria uma parte da vida social que seria o lócus da opressão das mulheres, das minorias sexuais e de determinados aspectos da personalidade humana nos indivíduos (Rubin, 1986). Essas idéias é que levam a autora a postular que a "revolução feminista profunda" libertaria não somente as mulheres, mas formas de expressão sexual diversas.

${ }^{17}$ Neste trabalho, Rubin considera que a divisão sexual do trabalho criaria homens e mulheres e os criaria heterossexuais. A supressão do componente homossexual da sexualidade humana e a opressão dos homossexuais seriam, desse modo, produtos do mesmo sistema cujas regras e relações oprimem as mulheres.
} 
Macho versus Macho

Em Thinking Sex, preocupada com a emergência de um movimento conservador que denomina de "pânico sexual", Rubin (1993) propõe elementos descritivos e conceituais para refletir sobre sexo e política. ${ }^{18}$ A autora desenvolve o conceito de estratificação sexual, por meio do qual postula que as sociedades ocidentais modernas avaliam os atos sexuais de acordo com um sistema hierárquico de valor sexual. ${ }^{19}$ Nessa estratificação, os estilos de sexualidade considerados "bons" (normais, naturais, saudáveis), tais como modalidades heterossexuais, no marco do casamento, monogâmicos, reprodutivos, se oporiam aos "maus", expressos nas práticas sexuais de travestis, transexuais, fetichistas, sadomasoquistas, no sexo comercial, por dinheiro, entre gerações, contando com áreas intermediárias. ${ }^{20}$ Dessa forma, Rubin afirma a relevância das sexualidades não reprodutivas no domínio da sexualidade. Além disso, ressalta a importância dos estudos

${ }^{18}$ Sua intenção seria contribuir para uma reflexão libertária sobre a sexualidade. Para isso, a autora coloca a necessidade de formular um inteligente e coerente corpus de pensamento radical sobre sexo, que possibilite o desenvolvimento de pontos de vista radicais sobre a sexualidade. O objetivo geral do ensaio seria propor elementos de um quadro descritivo e conceitual para refletir sobre sexo e política (Rubin, 1993). Sobre o contexto político que levou Rubin a formular essas idéias, ver a entrevista realizada com a autora por Judith Butler (2003) e Piscitelli et alii, 2004:Apresentação.

${ }^{19}$ Os casais heterossexuais, ligados pelo casamento, estariam sozinhos no topo da "pirâmide erótica". Abaixo deles, estariam os casais heterossexuais monogâmicos não casados, seguidos pelos/as heterossexuais com vida sexual ativa, porém casual. O sexo solitário viria acima de casais estáveis de lésbicas e de gays, que estariam "próximos da respeitabilidade". Lésbicas de bares e homossexuais "promíscuos" ficariam pouco acima dos grupos que ficam na parte mais baixa da pirâmide. As castas sexuais mais desprezadas atualmente seriam os transexuais, os travestis, os fetichistas, os sadomasoquistas, os/as trabalhadores/as do sexo e, abaixo de todos os outros, aqueles cujo erotismo ultrapassa as fronteiras de gerações ("pedófilos").

${ }^{20}$ É importante notar que, em nota de 1992, revisando o artigo para nova publicação, Rubin (1993) afirma que seu sistema classificatório não dá conta de todas as complexidades existentes, servindo apenas para fins de demonstração. As relações de poder no âmbito da variação sexual seriam muito mais complexas. 
acadêmicos sobre elas. Nos anos 90, assiste-se à profusão de chamados estudos gays e lésbicos, que, inspirados na autora, clamam pela distinção analítica entre gênero e sexualidade, ao mapearem criticamente a "estratificação sexual" presente nas sociedades modernas. Uma das críticas desses estudos é que, na análise de sexualidades heterossexuais, o gênero apareceria aprisionado numa distinção binária, na qual a sexualidade é atravessada por uma linha divisória entre homens e mulheres que parece estabelecer uma continuidade entre "sexo" e gênero. ${ }^{21} \mathrm{~A}$ noção de que existem práticas sexuais "boas" e "más" permeia boa parte dessa produção, que pensa o sexo como um vetor de opressão que atravessa outros modos de desigualdade social (classe, raça, etnicidade ou gênero). Para Piscitelli (2003:214-215),

na atualidade são, sobretudo, os estudos feitos da perspectiva gay e lésbica que parecem atualizar o espírito contestador de certas linhas do pensamento feminista em relação à sexualidade. Esses estudos, destacando a distinção entre sexualidade e reprodução, insistem veementemente na distinção analítica entre gênero $e$ sexualidade. ${ }^{22}$

A noção de estratificação sexual pode ser extremamente rentável para analisar as práticas homoeróticas aqui referidas. Por meio dela, é possível uma justificativa (teórica e política) de sua escolha como objeto de estudo, uma vez que estariam localizadas nas esferas mais baixas da "estratificação sexual". Acredito, porém, que um olhar sobre as teorias pós-estruturalistas ou pósmodernas possibilitem a (re)articulação entre gênero e sexualidade e um maior refinamento do propósito analítico de minha pesquisa.

${ }^{21}$ A esse respeito, ver Piscitelli, 2003.

${ }^{22}$ Vale lembrar que Judith Butler foi a primeira crítica da tendência geral dos queer studies de separação entre "teorias de sexualidade" e "teorias de gênero", focalizando as primeiras e deixando as segundas para o feminismo (Butler, 1997). Ver, também, Gregori, 2003. 
Macho versus Macho

\section{2 "Sexo" ou "Gênero", mas em maiúsculas}

Segundo Donna Haraway (2004), em todas as suas versões, as teorias feministas de gênero tentam articular a especificidade da opressão das mulheres no contexto de culturas nas quais as distinções entre sexo e gênero são marcantes, o que depende de um sistema relacionado de significados reunido em torno de uma família de pares de oposição: natureza/cultura, natureza/história, natural/humano, recursos/produtos. Apesar da rentabilidade (política e acadêmica) da distinção entre sexo e gênero no que diz respeito às sexualidades não-reprodutivas, algumas teorias mais recentes, inspiradas no desconstrutivismo ${ }^{23}$, apontam para os limites teóricos, políticos e epistemológicos da manutenção dessas dicotomias $e$, de diferentes maneiras, buscam alternativas analíticas relacionais. No geral, isso implica tanto em repensar a dualidade entre natureza e cultura (que persiste quando se pensa que o gênero seria a construção "cultural" do sexo visto como "natural"), quanto em abrir mão de teorias calcadas nas identidades e nos sujeitos para outras focadas na materialização dos corpos e nas subjetividades. Haraway, por exemplo, pontua que cresce a necessidade de uma teoria da "diferença" "cuja geometria, paradigmas e lógica escapem aos binarismos, à dialética, aos modelos natureza/cultura de todo tipo" (Haraway, 2004:206-207). Para a autora, se a distinção sexo/gênero permitiu ao pensamento de inspiração feminista argumentar contra o "determinismo biológico" e a favor do "construcionismo social", também impediu a desconstrução dos corpos, incluindo corpos "sexuados" e "racializados".

\footnotetext{
${ }^{23}$ Termo presente na filosofia e nas ciências sociais contemporâneas, que tem na obra do filósofo francês Jacques Derrida sua principal inspiração. A leitura desconstrutivista do chamado pensamento ocidental tem sido fonte para o desenvolvimento de muitas idéias do dito pós-estruturalismo em ciências humanas, inspirando, ainda, boa parte da teoria queer, sobretudo nos países anglófonos.
} 
Henrietta Moore (1997) baseia-se nas idéias de Yanagisako e Collier (1987) para questionar a distinção sexo/gênero. A diferença de sexo tomada como natural, pré-social, comporia o modelo nativo ocidental que se apóia numa diferença sexual binária, de base biológica, que basearia as análises antropológicas. Para as autoras, tanto o sexo quanto o gênero são socialmente construídos, um em relação ao outro. Os corpos, os processos psicológicos e mesmo as partes do corpo não teriam sentido fora das compreensões socialmente construídas a seu respeito. De modo análogo, não faria sentido falar num sexo "anterior" ao social, na medida em que o "sexo" (no limite, qualquer outro "objeto") só existiria dentro dos discursos que o produzem. ${ }^{24}$ As autoras concluem que se reconhecemos que o conceito ocidental de sexo é socialmente construído, não podemos argumentar que esse modelo particular de sexo "biológico" constitui em toda parte o "material cru" das construções de gênero, tampouco fornece em toda parte a base para a compreensão dos processos de reprodução humana.

Essas idéias são retomadas por Errington, de acordo com Moore, para categorizar o Sexo (em maiúsculo): uma construção particular dos corpos humanos. E o gênero se referiria ao "quê" as diferentes culturas fazem do sexo (em minúsculo). O problema, para Moore, é que essas autoras parecem não conceber que o sexo (materialidade, em minúsculo), em toda parte, é Sexo (matriz, em maiúsculo) e, embora a constituição, a configuração $e$ os efeitos particulares do sexo sejam claramente variáveis entre as culturas, não há outra maneira de conhecer o sexo senão através do Sexo. O Sexo passa a ser, então, uma matriz de inteligibilidade dos corpos sexuados. A própria noção de sexo biológico seria o produto do discurso biomédico da cultura ocidental. Não faria sentido, portanto, insistir na separação de sexo e gênero, quando

\footnotetext{
${ }^{24}$ Essas autoras trabalham na linha foucaultiana, o que implica pensar que tanto o sexo quanto o gênero não são origens, mas produtos de práticas discursivas específicas, que compõem o dispositivo da sexualidade (Foucault, 1977).
} 
Macho versus Macho

a questão real não é sexo, e sim "Sexo" (Moore, 1997). A determinação de duas categorias fixas e mutuamente exclusivas de sexo, a fêmea e o macho, seria um efeito do discurso cultural ocidental do "Sexo".

Essa é uma maneira de conceituar o modo como os corpos são materializados dentro de uma matriz de inteligibilidade - no caso, a heterossexualidade compulsória -, que estabelece a necessidade da coerência entre categorias diferenciadas para que os sujeitos possam ser inteligíveis, no limite, para ter existência enquanto sujeito. Se Moore chama essa matriz de "Sexo", Judith Butler a nomeia Gênero.

Em Problemas de Gênero, Butler (2003a) busca facilitar a convergência entre as perspectivas feministas, gays e lésbicas sobre o gênero com a teoria pós-estruturalista. A autora desenvolve uma "teoria performativa" de atos de gênero que rompem as categorias de corpo, sexo, gênero e sexualidade, "ocasionando sua re-significação subversiva e sua proliferação além da estrutura binária" (Id. ib.:11). Em outro texto, a autora explica que a "performatividade" deve ser entendida não como um "ato" singular e deliberado, mas antes como a prática reiterativa e referencial mediante a qual o discurso produz os efeitos que nomeia. As normas reguladoras do "sexo" agiriam de uma maneira performativa para construir a materialidade dos corpos e, mais especificamente, para materializar o sexo do corpo, a diferença sexual, visando consolidar o imperativo heterossexual (Butler, 2002). Para Butler, o gênero deve ser entendido como uma espécie de imitação persistente, que passa como real. ${ }^{25} \mathrm{O}$ gênero

\footnotetext{
${ }^{25}$ Inspirada em Foucault, a autora busca uma perspectiva crítica baseada na noção de genealogia. A crítica genealógica recusa-se a buscar as origens do gênero, a verdade íntima do desejo feminino, uma identidade sexual genuína ou autêntica que a repressão impede de ver; em vez disso, ela investiga as apostas políticas, designando como origem e causa categorias de identidade que, na verdade, são efeitos de instituições, práticas e discursos cujos pontos de origem são múltiplos e difusos (Butler, 2003a). É isso que a faz defender uma política feminista que tome a construção variável da identidade como um pré-requisito metodológico e normativo, senão como um objetivo político.
} 
seria a estilização repetida do corpo, um conjunto de atos repetidos no interior de uma estrutura reguladora altamente rígida, a qual se cristaliza no tempo para produzir a aparência de uma substância, de uma classe natural de ser.

Quando o status construído do gênero é teorizado como radicalmente independente do sexo, o próprio gênero se torna um artifício flutuante, com a conseqüência de que homem e masculino podem, com igual facilidade, significar tanto um corpo feminino como um masculino, e mulher $e$ feminino, tanto um corpo masculino como um feminino (Butler, 2003a:24-25).

De acordo com a autora, não faz sentido definir o gênero como "a interpretação cultural do sexo", pois a produção do sexo como "pré-discursivo" deve ser compreendida como efeito do Gênero, entendido como um aparato de construção cultural. Ela recoloca, dessa maneira, a problemática do gênero no estudo das sexualidades, ao menos no sentido foucaultiano. Mas o faz por meio de um entendimento muito peculiar do que seria o "gênero": um aparato, uma matriz de inteligibilidade cultural. ${ }^{26 .}$ Em Butler, tanto o gênero, quanto o sexo e mesmo o corpo não podem ser entendidos como "anteriores à lei", ou como "recipientes passivos de uma lei cultural inexorável". A "coerência" e a "continuidade" da "pessoa" não seriam características lógicas ou analíticas da condição de pessoa, mas, ao contrário, normas de inteligibilidade socialmente instituídas $e$ mantidas.

Gêneros "inteligíveis" são aqueles que, em certo sentido, instituem e mantêm relações de coerência e continuidade entre sexo, gênero, prática sexual e desejo. Em outras

26 "Se o caráter imutável do sexo é contestável, talvez o próprio construto chamado 'sexo' seja tão culturalmente construído quanto o gênero; a rigor, talvez o sexo sempre tenha sido o gênero, de tal forma que a distinção entre sexo e gênero revela-se absolutamente nenhuma" (Id. ib.:25). 
Macho versus Macho

palavras, os espectros de descontinuidade e incoerência, eles próprios só concebíveis em relação a normas existentes de continuidade e coerência, são constantemente proibidos $e$ produzidos pelas próprias leis que buscam estabelecer linhas causais ou expressivas de ligação entre o sexo biológico, o gênero culturalmente constituído e a "expressão" ou "efeito" de ambos na manifestação do desejo sexual por meio da prática sexual (Id. ib.:38).

Para Butler, a "heterossexualização do desejo" requer $e$ institui a produção de oposições discriminadas e assimétricas entre "feminino" e "masculino", compreendidos como atributos expressivos de "macho" e de "fêmea". O efeito substantivo do gênero seria performativamente produzido e imposto pelas práticas reguladoras da coerência do gênero. A identidade de gênero (relação "coerente" entre sexo, gênero, prática sexual e desejo) seria o efeito de uma prática reguladora que pode ser identificada como heterossexualidade compulsória. ${ }^{27}$ Desse modo, a matriz cultural (Gênero), por intermédio da qual a identidade de gênero $^{28}$ se torna inteligível, exigiria que certos tipos de "identidade" (por exemplo, sexual) não possam "existir" - isto é, aquelas em que o gênero não decorre do sexo e aquelas em que as práticas do desejo não "decorrem" nem do "sexo" nem do "gênero". Certos tipos de "identidade de gênero" seriam impossibilidades lógicas, pois não se conformam às normas da inteligibilidade cultural. A sexualidade seria construída culturalmente nas relações de poder. Desse modo, a postulação

27 "A coerência ou a unidade internas de qualquer dos gêneros, homem ou mulher, exigem assim uma heterossexualidade estável e oposicional (...) Essa concepção do gênero não só pressupõe uma relação causal entre sexo, gênero $e$ desejo, mas sugere igualmente que o desejo reflete ou exprime o gênero, e que o gênero reflete ou exprime o desejo" (Id. ib.:45).

${ }^{28}$ Para Butler, seria errado supor que a discussão sobre a "identidade" deve ser anterior à discussão sobre a identidade de gênero, pois as "pessoas" só se tornariam "inteligíveis" ao adquirir seu gênero em conformidade com padrões reconhecíveis de inteligibilidade do gênero. 
de uma sexualidade normativa "antes", "fora" ou "além" do poder constitui, para Butler, uma "impossibilidade cultural", "politicamente impraticável". A questão seria, então, perguntar sobre as possibilidades subversivas da sexualidade e da identidade nos próprios termos do poder. A "repetição" das normas da matriz cultural hegemônica de inteligibilidade, que ela chama de Gênero, estaria fadada a persistir como mecanismo da reprodução cultural das identidades. ${ }^{29} \mathrm{~A}$ partir daí, a autora se questiona sobre o tipo de repetição subversiva que poderia questionar a própria prática reguladora da identidade. ${ }^{30}$ As transgressões, aquilo que do ponto de vista normativo é "intratável", tornam-se interessantes para pensar as mudanças. O interdito, em Butler, é tomado como possibilidade aberta, evocando uma criatividade subversiva. ${ }^{31}$

As "produções" (dentro da matriz) se desviariam de seus propósitos originais e mobilizariam inadvertidamente possibilidades de sujeitos "que não apenas ultrapassam os limites da inteligibilidade cultural como efetivamente expandem as fronteiras do que é de fato culturalmente inteligível" (Butler, 2003a:54). A persistência e proliferação das identidades de gênero "logicamente impossíveis" criariam

oportunidades críticas de expor os limites e os objetivos reguladores desse campo de inteligibilidade $e$, conseqüentemente, de disseminar, nos próprios termos

\footnotetext{
29 "Como em outros dramas sociais rituais, a ação do gênero requer uma performance repetida. Essa repetição é a um só tempo reencenação e nova experiência de um conjunto de significados já estabelecidos socialmente; e também a forma mundana e ritualizada de sua legitimação" (Butler, 2003a:200).

${ }^{30}$ Essas idéias lhe permitem tomar as drag-queens como exemplos de práticas potencialmente subversivas, pois seus atos corporais exporiam o "feminino" como um pastiche.

${ }^{31}$ É por isso que a autora busca como referencial as idéias de Austin. No plano lingüístico, Austin (1980) permite perceber como os sentidos das palavras não são dados de antemão, mas construídos na relação que os termos estabelecem contextualmente. Essa noção de "incompletude" e de abertura dos termos é interessante para Butler.
} 
Macho versus Macho

dessa matriz de inteligibilidade, matrizes rivais e subversivas de desordem do gênero (Id. ib.:39).

Para Butler, as regras que governam a significação não só restringem, mas permitem a afirmação de campos alternativos de inteligibilidade cultural, i.e., novas possibilidades de gênero que contestem os códigos rígidos dos binarismos hierárquicos. Desse modo, ela se questiona acerca da proliferação das configurações de gênero fora das estruturas restritivas da "dominação masculinista" e da "heterossexualidade compulsória". ${ }^{32}$ Em seus termos,

A construção de contornos corporais estáveis repousa sobre lugares fixos de permeabilidade $e$ impermeabilidade corporais. As práticas sexuais que abrem ou fecham superfícies ou orifícios à significação erótica em ambos os contextos, homossexual e heterossexual, reinscrevem efetivamente as fronteiras do corpo em conformidade com novas linhas culturais (Butler, 2003a:190).

A heterossexualidade normativa seria um dos regimes reguladores que operam na produção dos contornos corporais ou na fixação dos limites da inteligibilidade corporal (Id., 2002). Se o corpo, para a autora, não é uma superfície pronta à espera de significação, mas "um conjunto de fronteiras, individuais e sociais, politicamente significadas e mantidas" (Butler, 2003a:59), o sexo anal $e$ oral entre homens evoca uma noção de permeabilidade

${ }^{32}$ A questão seria, então, descobrir "que possibilidades existem de configurações de gênero entre as várias matrizes emergentes - e às vezes convergentes - da inteligibilidade cultural que rege a vida marcada pelo gênero" (Id. ib.:56). Em outro texto, Butler afirma que o "sexo" é uma construção ideal que se materializa obrigatoriamente através do tempo. É um processo - a materialização nunca é completa. Para ela, as instabilidades, as possibilidades de rematerialização abertas por esse processo, marcam um espaço no qual a força da lei reguladora pode voltar-se contra si mesma, produzindo rearticulações que ponham em tela de juízo a força hegemônica dessas mesmas leis reguladoras (Butler, 2002). 
corporal não sancionada pela ordem hegemônica. A homossexualidade masculina seria, do ponto de vista hegemônico, um lugar de "perigo e poluição".

\section{3 - Subjetividades contingentes}

Enfatizo que perspectivas como a de Butler, ou de autores/as que poderíamos colocar sob a rubrica do "pósmodernismo" ou do "pós-estruturalismo" (quando bem lidas), não descartam os "fundamentos" ou "substâncias" - trata-se, antes, de mostrar como eles não são o ponto de partida analítico (não estão "lá desde sempre"), mas sim o efeito de práticas discursivas contextualmente dadas que operam na materialização dos corpos e na produção de subjetividades tidas como coerentes, inteligíveis, dentro das matrizes (discursivas) de poder.

É esse movimento que autoras como Strathern (1996) e Toren (1996) fazem com o conceito de sociedade (enquanto totalidade integrada) em Antropologia. Questionando conceitos adjacentes ao de sociedade, as autoras buscam um vocabulário alternativo, defendendo o uso de "socialidade": pessoas "existindo" por meio de relações e as criando em suas ações societais. O interessante é observar que a noção de socialidade não "joga fora" a noção de sociedade: trata-se de uma desconstrução do termo. No limite, a socialidade deriva da sociedade, mas a tendo como uma espécie de "pano de fundo" contingente (Toren, 1996). Essa maneira de pensar a socialidade e a existência dos objetos em matrizes relacionais está presente em Gênero da Dádiva, trabalho de Strathern (1988) que parte de um balanço de etnografias antropológicas produzidas sobre a Melanésia para desenvolver seus argumentos sobre uma teoria de gênero relacional. A autora enfatiza que a noção de indivíduo não é cabível no caso melanésio. Seu foco passa a ser na constituição da pessoa, tomando os agentes empíricos como seres "dividuais" (Id. ib.). Acredito que Strathern possa ser apontada como uma das autoras que contribuíram para o desenvolvimento das linhas pós- 
Macho versus Macho

estruturalistas ou pós-modernas nos estudos de gênero $e$ sexualidade.

Entre as correntes dos feminismos europeus pós 68, Haraway destaca autoras como Irigaray, Kristeva e Cixous (apoiadas tanto no desconstrutivismo de Derrida, como nas críticas de Freud via Lacan), que insistem que o sujeito, que talvez seja melhor percebido através da escrita e da textualidade, está sempre em processo, sempre estilhaçado, e que a idéia de mulher deva permanecer aberta e múltipla.

A preferência pela psicanálise das relações objetais contra a versão lacaniana relaciona-se com conceitos vizinhos como "identidade de gênero", com sua rede de significados da ciência social empírica, que é diferente da "aquisição de posições de subjetividade sexuada", conceito este imerso na teoria cultural/textual do continente (Haraway, 2004:234).

A recusa em tornar-se ou permanecer homem ou mulher marcado/a pelo gênero é, então, uma insistência eminentemente política em sair do pesadelo da "muito-real narrativa imaginária de sexo e raça" (Id. ib.). Para a autora, o poder político e explicativo da categoria "social" gênero depende da historicização das categorias sexo, carne, corpo, biologia, raça e natureza, de tal modo que as oposições binárias, universalizantes, que geraram o conceito de sistema de sexo/gênero num momento e num lugar particular na teoria feminista sejam implodidas em

teorias da corporificação articuladas, diferenciadas, responsáveis, localizadas e com conseqüências, nas quais a natureza não mais seja imaginada e representada como recurso para a cultura ou o sexo para o gênero (Id. ib.:246).

Esse argumento é semelhante ao de Judith Butler (2003a), ao questionar a necessidade de um sujeito político estável $e$ coerente para a prática feminista. Ela argumenta que o discurso de identidade de gênero é intrínseco às ficções de coerência 
heterossexual e que o feminismo precisa aprender a produzir uma legitimidade narrativa para todo um conjunto de gêneros não coerentes. A tarefa seria desconstruir as categorias analíticas, como sexo ou natureza, que levam à univocidade, à substancialidade. Haraway lembra que

muitas feministas resistem a propostas como a de Butler por medo de perder um conceito de atuação para as mulheres, já que o conceito de sujeito murcha sob o ataque às identidades centradas $e$ às ficções que as constituem (Haraway, 2004:219).

Butler, entretanto, argumenta que o conceito de um "eu" interior coerente, adquirido (culturalmente) ou inato (biológico), é uma ficção reguladora desnecessária - de fato, inibidora - aos projetos feministas. Para a autora, o "eu" é constituído por posições, é situado, e essas "posições" não são meros produtos teóricos, mas "princípios organizadores embutidos de práticas materiais $e$ arranjos institucionais, que são as matrizes de poder e discurso que me produzem como um 'sujeito' viável" (Butler, 1997). Isso significa não tomar o sujeito como um ponto de partida. A crítica do sujeito não é uma negação ou repúdio a ele, mas um modo de interrogar sobre sua construção como dada de antemão. Para a autora, a "desconstrução" implica apenas que suspendemos todos os compromissos com aquilo a que o termo "o sujeito" se refere, $e$ que examinamos as funções lingüísticas a que ele serve na consolidação e ocultamento da autoridade. Desconstruir não é negar ou descartar, mas pôr em questão e "abrir" um termo (como "o" sujeito) a uma reutilização e uma redistribuição anteriormente não autorizadas (Id. ib.). Do mesmo modo, desconstruir a materialidade dos corpos significa apenas suspender e problematizar o referente ontológico tradicional do termo, o que proporcionaria um meio para mobilizar o significante a serviço de produções corporais (ou materializações) alternativas (Id. ib.). Isso significa pensar tanto as materializações dos corpos 
Macho versus Macho

quanto a produção das subjetividades como contingentes: a possibilidade de existência (ou a "abjeção") dos corpos e dos "sujeitos" depende da matriz discursiva de inteligibilidade.

\section{Considerações finais...}

Se, a princípio, é tentador pensar que tal explosão discursiva valorativa da masculinidade entre homens com práticas homoeróticas significa uma reposição de normas, convenções ou estereótipos tradicionais de gênero, o fato de ela se dar em contextos de sociabilidade homoerótica não é banal. Por mais questionável do ponto de vista das hierarquias que coloca, a hiper-valorização da masculinidade ou a criação discursiva do "macho" como objeto de desejo entre esses homens (e de um macho que não perde sua "macheza" ao ser penetrado) pode ser lida como rearticulação ou deslocamento de convenções relativas a sexo, gênero e desejo que compõem a matriz heteronormativa culturalmente hegemônica, como se esses atos corporais servissem para pensar também o masculino como um pastiche. Por outro lado, fica evidente também que tal processo implica na criação de novos modos de hierarquização e de inteligibilidade. Um exemplo é a rejeição, de determinados segmentos do chamado "Circuito GLS" paulistano, aos garotos pobres moradores da periferia apelidados, pejorativamente, "bichinhas poc poc" ou "bichas pãocom-ovo", tomados como "afeminados" (Simões e França, 2005). Nessa taxonomia são acionados diferentes marcadores, não apenas de gênero e sexualidade, mas de classe, estilo, raça, gramática corporal, o que me levou a etnografar espaços para sexo localizados em diferentes lugares na cidade. Outro exemplo é relatado por Túlio. Certa vez, ele combinou, via bate-papo eletrônico, uma orgia com seis homens do Rio de Janeiro (em que ele seria a "Bola da Vez"). Esses homens se diziam "machos", "dominadores", "ativos". Chegando ao Rio de Janeiro, Túlio se deparou com "seis garotos magrinhos", na faixa dos vinte anos, alguns deles até meio "afeminados", que não correspondiam à 
figura do "macho dominador" que esperava encontrar. Isso fez com que ele voltasse para São Paulo "na hora, sem dizer uma palavra". Este relato suscita a questão de como os sujeitos são contextualmente materializados, ou seja, como são criadas as possibilidades de sua existência dentro do "mercado do sexo" entre homens. A hipótese desta pesquisa é que a produção do "macho" como objeto de desejo é um dos elementos dessa materialização, na qual se articulam não apenas marcadores de gênero e sexualidade, ou convenções relativas a posições sexuais (ativo/passivo), mas uma série de outros marcadores, raciais, etários, de classe e até mesmo relativos à obesidade (se pensamos na necessidade de um "corpo proporcional à altura", o que me leva a pensar, para tomar apenas um exemplo, que nas práticas sadomasoquistas do Clube $\mathrm{X}$, nem toda nudez será castigada...). Concordando com boa parte do pensamento de inspiração antropológico-feminista contemporâneo, que toma a diferença como categoria analítica (Moore, 1996) e aponta a necessidade de pensar a intersecção de diversos marcadores na produção contextual e relacional das subjetividades (Brah, 1996), acredito que um olhar relacional $e$ interseccional é fundamental para entender as nuances implicadas no "sexo entre machos". Olhar para os "machos" em questão e perceber como eles "vêm a ser" talvez seja importante para pensar no versus que os relaciona.

\section{Referências bibliográficas}

Austin, John L. Quando dizer é fazer - Palauras e Ação. Porto Alegre, Artes Médicas, 1980.

BatAille, Georges. O Erotismo. Porto Alegre, L\&PM Editores, 1987.

BlANCHOT, Maurice. Pena de Morte. Rio de Janeiro, Imago, 2006.

BRAH, Avtar. Difference, Diversity, Differentiation. Cartographies of Diaspora: Contesting Indentities. Longon/New York, Routledge, 1996.

BUTLER, Judith. O parentesco é sempre tido como heterossexual? cadernos pagu (21), Núcleo de Estudos de Gênero - Pagu/Unicamp, 2003, pp.219-260. 
Macho versus Macho

Problemas de gênero: feminismo e subversão da identidade. Rio de Janeiro, Civilização Brasileira, 2003a.

\& RUBIN, Gayle. Tráfico sexual - entrevista (Gayle Rubin com Judith Butler). cadernos pagu (21), Núcleo de Estudos de Gênero - Pagu/Unicamp, 2003, pp.157-209.

Cuerpos que importan - Sobre os límites materiales y discursivos del "sexo". Buenos Aires/Barcelona, México, Paidos, 2002.

Against Proper Objects. In: LEED, Elizabeth \& SCHOR, Naomi. Feminism meets queer theory. EUA, Indiana University Press, 1997.

CARTER, Angela. The Sadeian Woman - and the ideology of pornography. New York, Pantheon Books, 1978.

CITELI, Maria Teresa. A pesquisa sobre sexualidade e direitos sexuais no Brasil (1990-2002): revisão crítica. Rio de Janeiro, CEPESC, 2005.

DELEUZE, Gilles. Apresentação de Sacher-Masoch - o frio e o cruel. Rio de Janeiro, Taurus, 1983.

Douglas, Mary. Pureza e Perigo. São Paulo, Perspectivas, 1976.

DUARTE, Luiz Fernando Dias. A Sexualidade nas Ciências Sociais: leitura crítica das convenções. In: PISCITELLI et alii. (orgs.) Sexualidade e Saberes: Convenções e Fronteiras. Rio de Janeiro, Garamond Universitária, 2004.

FACCHINI, Regina. Entrecruzando diferenças: corporalidade e identidade entre mulheres com práticas homoeróticas na Grande São Paulo. Comunicação apresentada na $25^{a}$. RBA - Reunião Brasileira de Antropologia, Goiânia, 2006.

FouCAUlt, Michel. História da Sexualidade I. A vontade de Saber. Rio de Janeiro, Graal, 1977.

FRANÇA, Isadora Lins. Cercas e pontes. O movimento GLBT e o mercado GLS na cidade de São Paulo. Dissertação de mestrado, Antropologia Social, USP, 2006.

FRY, Peter. Para Inglês Ver: identidade e política na cultura brasileira. Rio de Janeiro, Zahar, 1982. 
GALLOP, Jane. Friendship, a small number of exceptions: Bataille on Sade. Intersections - a reading of Sade with Bataille, Blanchot and Klossowski. London, University of Nebraska Press, 1981.

GREGORI, Maria Filomena. Prazer e Perigo: notas sobre feminismo, sexshops e s/m. In: PISCITELLI et alii. (orgs.) Sexualidade e Saberes: Convenções e Fronteiras. Rio de Janeiro, Garamond Universitária, 2004.

Relações de violência e erotismo. cadernos pagu (20), Núcleo de Estudos de Gênero - Pagu/Unicamp, 2003.

HARAWAY, Donna. "Gênero" para um dicionário marxista: a política sexual de uma palavra. cadernos pagu (22), Núcleo de Estudos de Gênero - Pagu/Unicamp, 2004.

KRISTEVA, Julia. From Filth to Defilement. In: Powers of Horror - an essay on abjection. New York, Columbia University Press, 1982.

MACCLINTOCK, Anne. Couro Imperial - Raça, travestismo e o culto da domesticidade. cadernos pagu (20), Núcleo de Estudos de Gênero Pagu/Unicamp, 2003.

. Maid to Order - Commercial S/M and gender power. In: GIBSON, Pamela; GiBSON, Roma. Dirty Looks - Women, pornography, power. London, BFI Publishing, 1994.

MOORE, Henrietta. Understanding sex and gender. In: INGOLD, Tim. (ed.) Companion Encyclopedia of Anthropology. Londres, Routledge, 1997.

. Antropología y feminismo. Madri, Cátedra, 1996.

Piscitelli, A.; Gregori, M. F.; Carrara, S. (orgs.) Sexualidade $e$ saberes: convenções e fronteiras. Rio de Janeiro, Garamond, 2004.

Comentário. cadernos pagu (21), Núcleo de Estudos de Gênero - Pagu/Unicamp, 2003, pp.211-218.

RuBIN, Gayle. Thinking Sex: Notes for a Radical Theory of the Politics of Sexuality. In: ABElOVE, Henry; BARALE, Michèle; HalPERIN, David. (eds.) The Lesbian and Gay Studies Reader. Nova York, Routledge, 1993 [1984].

El Tráfico de Mujeres: notas sobre la "economia política" del sexo. Revista Nueva Antropología (30, VIII), México, 1986, pp.95145 . 
Macho versus Macho

SIMÕES, Júlio Assis. Homossexualidade Masculina e Curso da Vida: pensando idades e identidades sexuais. In: PISCITELLI et alii. (orgs.) Sexualidade e Saberes: Convenções e Fronteiras. Rio de Janeiro, Garamond Universitária, 2004.

e FRANÇA, Isadora Lins. Do Gueto ao mercado. In: GREEN, James Naylor; TRINDADE, Ronaldo. (orgs.) Homossexualismo em São Paulo e outros escritos. São Paulo, Editora Unesp, 2005.

StRATHERn, Marilyn. For the Motion (1). In: INGOLd, Tim (ed.). Key Debates in Anthropology. London, Routledge, 1996.

The Gender of the Gift: Problems with Women and Problems with Society in Melanesia. EUA, University of California Press, 1988 [Gênero da dádiva: problemas com as mulheres $e$ problemas com a sociedade melanésia. Campinas-SP, Editora da Unicamp, 2006 (trad.: André Villalobos)].

TorEn, Christina. For the Motion (2). In: INGOLD, Tim. (ed.) Key Debates in Anthropology. London, Routledge, 1996.

VIANNA, Adriana \& LACERDA, Paula. Direitos e políticas sexuais no Brasil: o panorama atual. Rio de Janeiro, CEPESC, 2004.

YANAGISAKO, Sylvia e COLLIER, Jane. Toward a unified theory of gender and kinship. In: YANAGISAKO e COLLIER. (orgs.) Genger and Kinship: Essays Toward an Unified Analysis. Stanford, Stanford University Press, 1987.

ZILLI, Bruno Dallacort. O Perverso Domesticado: da patologia à diversidade sexual num estudo sobre o discurso "BDSM" na internet. $30^{\circ}$ Encontro Anual da Anpocs (CD-ROM), Caxambu, 2006. 